\title{
EC/OC and PAHs Emissions from a Modern Diesel Engine with DPF Regeneration Fueled by 10\% RME Biodiesel
}

\author{
Keiko Shibata $^{1^{*}}$, Kenji Enya ${ }^{2}$, Naoya Ishikawa ${ }^{1}$, Kazuhiko Sakamoto ${ }^{3}$ \\ ${ }^{1}$ 2nd Research Department, Isuzu Advanced Engineering Center, Ltd., Kanagawa 252-0881, Japan \\ ${ }^{2}$ New A.C.E Institute Co., Ltd., Ibaraki 305-0822, Japan \\ ${ }^{3}$ Asia Center for Air Pollution Research (ACAP), Japan Environmental Sanitation Center, Niigata 950-2144, Japan
}

\begin{abstract}
In this study, the effect of using a blended biodiesel fuel containing $10 \%$ rapeseed methyl ester (RME) on the composition and quantity of the chemicals emitted by a modern diesel engine was investigated. The diesel engine that was utilized fulfilled Japan's Post New Long Term emission standards and was equipped with an after-treatment system comprising a diesel oxidation catalyst and a catalyzed diesel particulate filter (c-DPF). Using the Japanese JE05 transient cycle as the testing cycle, the exhaust gas was sampled for three different states: when the after-treatment system was not deployed, termed "engine-out" (due to the sampling location); when the after-treatment system was deployed, termed "tailpipe-out" (likewise due the sampling location); and when the after-treatment system was deployed and the c-DPF was regenerating, termed "regen". Evidence from this study indicated that the use of 10\% RME biodiesel had no significant impact on the emissions of $\mathrm{CO}, \mathrm{CO}_{2}$, the total hydrocarbons, and $\mathrm{NO}_{\mathrm{x}}$, which are regulated, regardless of the sampling state. However, the emissions of elemental carbon, organic carbon, and polycyclic aromatic hydrocarbons (PAHs), which are unregulated, showed some effects. During engine-out and tailpipe-out, emissions of the elemental carbon species EC2 were slightly lower when using the biodiesel blend than the petroleum diesel (D) fuel; however, an increase in the organic carbon species $\mathrm{OC} 1$ and $\mathrm{OC} 2$ and in some PAHs was observed during regen because of the sizable consumption of the biodiesel blend compared to $\mathrm{D}$ fuel. These results confirm that $10 \% \mathrm{RME}$ biodiesel is a promising alternative to fossil fuels for diesel engines, but it is important to grasp the behavior of individual components and carefully investigate the effects of increased mixing ratios.
\end{abstract}

Keywords: Particle composition; Engine-out; Tailpipe-out; Thermal desorption gas chromatography-mass spectrometry.

\section{INTRODUCTION}

Biodiesel is regarded as an alternative to fossil fuels for powering compression ignition (CI) engines because this type of fuel is renewable, carbon-neutral, and biodegradable. Biodiesel is almost entirely made from edible vegetable oils (e.g., soybean, palm, and sunflower oils), and plant seed oils (e.g., rapeseed and linseed oils). Research focusing on biodiesel and aimed at addressing the air pollution and global warming resulting from the use of fossil fuels is actively being pursued around the world. Additional characteristics that render biodiesel appealing from a research and environmental standpoint are that it has a narrower boiling range than petroleum diesel (D) fuel, as well as a higher viscosity and cetane number, in conjunction

\footnotetext{
* Corresponding author.

Tel.: +81-46-645-2614; Fax: +81-46-645-2405

E-mail address: keiko@iaec.isuzu.co.jp
}

with a lower volatility (Zheng et al., 2006; He et al., 2016). Reports published over the past few years indicate that the volume-based ranking of vegetable oil is as follows: soybean oil is the most widely produced vegetable oil, followed by palm oil and then rapeseed. Because of higher productivity per area and lower production cost, palm oil is one of the most appealing raw materials for biodiesel production. Soybean oil methyl ester is currently commercially available in the United States, whereas rapeseed methyl ester (RME) is available in some European countries (Kinoshita et al., 2006). In Europe, biodiesel is mostly manufactured to meet the requirements (He et al., 2016).

Given that, in general, at a molecular level biodiesel contains more oxygen atoms than $\mathrm{D}$ fuel, biodiesel-associated $\mathrm{NO}_{\mathrm{x}}$ emissions can also be higher than D fuel's emissions (Babu et al., 2003; Sze et al., 2007; Robbins et al., 2011). Zhong et al. found that the ignition delay decreased with the increasing blending ratio of second-generation biodiesel (SGB), such as non-edible feedstocks, waste or recycle oils, and animal fats, as cetane number is an important factor for affecting the ignition delay. They concluded that when 
SGB blends in fuel, it reduces $\mathrm{NO}_{\mathrm{x}}$; however, the use of SGB can weaken the trade-off relation between particulate matter (PM) and $\mathrm{NO}_{\mathrm{x}}$. This is thought to be an advantage to solve the problems related to first-generation biodiesel.

Most of the studies concentrating on emissions originating from CI engines powered by biodiesel focused on regulated pollutants, such as particulate matter (PM), total hydrocarbons (THC), $\mathrm{NO}_{\mathrm{x}}$, and $\mathrm{CO}$ (Zhang et al., 2011). The size of PM is also an important factor for affecting human health. Peters et al. (1997) conducted a short-term research on epidemiology. Their results indicated that size distribution of ambient particles helps to elucidate the properties of ambient aerosols responsible for the effects on human health. Chien et al. (2009) measured the size distribution of PM and PAHs. Furthermore, they indicated that for most biodiesel blending mixtures in four size ranges, the percentages of PAH emission reduction were higher than those of PM emission. Ajtai et al. (2016) reported that the ratio of biodiesel to petroleum diesel in the total fuel blend can influence both the total number and volume concentration and distribution of the particle emission. The total number and volume concentration emitted by the diesel engine decreased with increasing revolutions per minute and rated torque for the engine for all fuel blend types. Their observations revealed that the extent of the biodiesel content in the total fuel amount can influence the total volume and number of emitted particulates.

Over the past few years, furthermore, some researchers have focused attention on the effect that biodiesel fuels with different structures have on the effectiveness of exhaust after-treatment systems. Development of biodiesel fuels can be a powerful tool to further reduce the diesel exhaust gas and particle emissions and to fulfill the requirement of the continuously changing strict emission standards of the world. From the viewpoint of health effects, it is necessary to evaluate the emission inventory and future emission projection of diesel and biodiesel-powered vehicles, including the regeneration of DPF. However, literature focusing on the influence that active regeneration by diesel particulate filter (DPF) has on the chemical components of PM emitted by an engine operating on biodiesel fuel is very scarce.

This present study concentrates on evaluating the emissions of carbonaceous components and particle-phase polycyclic aromatic hydrocarbons (PAHs) with a diesel engine powered by either a 10\% RME biodiesel blend or a $\mathrm{D}$ fuel. In particular, three engine operating conditions were utilized in our research: without the after-treatment system, termed "engine-out"; with the after-treatment system, termed "tailpipe-out"; and during the active regeneration of the catalyzed diesel particulate filter (c-DPF), termed "regen," under the Japanese JE05 transient test cycle. This research is useful for finding the best countermeasure, such as adding a heat generation improver, for example, an electrically heated catalyst, by investigating the ignition delay issue increasing the future biofuel mixing ratios.

\section{METHODS}

\section{Test Engine and Operating Conditions}

The test engine utilized in the present study consisted of a four-cylinder direct-injection diesel engine with a turbocharger, an intercooler, and an after-treatment system, which meets Japan's Post New Long Term emission regulations. The after-treatment system was made up of a diesel oxidation catalyst (DOC) and a c-DPF. Table 1 lists detailed specifications of the test engine. DOC catalyzes the oxidation of $\mathrm{CO}, \mathrm{NO}$, and hydrocarbons ( $\mathrm{HC})$. The engine was operated on an engine dynamometer according to the Japanese JE05 transient cycle for 1830 seconds, implementing three different engine operating conditions: without the after-treatment system (engine-out); with the after-treatment system (tailpipe-out); and during active regeneration with the after-treatment system (regen).

The c-DPF is a wall-flow-type filter coated with precious metal. The c-DPF regeneration starts by determining whether or not the differential pressure between the inlet and the outlet of the c-DPF itself is smaller or greater than a certain value. The burning of the accumulated soot in the c-DPF is possible using the heat supplied by the exhaust gas. Accumulated soot can be burned with the target temperature for c-DPF regeneration set in advance. The temperature of the exhaust gas is made to rise by the DOCeffected oxidation of the fuel injected into the exhaust pipe at the position of the inlet of the DOC. Regeneration started at the beginning of the JE05 test cycle, and it proceeded for about one third of the length of the JE05 test. Before performing the test of the regeneration conditions, c-DPF was treated at high temperature in order to remove all the soot collected within it by electric furnace; subsequently, the JE05 test cycle was repeated eight times. Active regeneration was initiated at the ninth JE05 test cycle. The test engine and particle sampling system are depicted in Fig. 1 for the example case of the regen conditions.

\section{Test Fuels}

In the present study, we used a 10\% RME biodiesel blend

Table 1. Specification of the test engine.

\begin{tabular}{ll}
\hline Engine displacement & $2.99 \mathrm{~L}$ \\
\hline Cylinder arrangement & Inline, four cylinders, turbocharged \\
Bore $\times$ stroke & $\varphi 95.4 \mathrm{~mm} \times 104.9 \mathrm{~mm}$ \\
Compression ratio & 17.5 \\
Max. power & $110 \mathrm{~kW} / 2800 \mathrm{rpm}$ \\
Max. torque & $375 \mathrm{Nm} / 1600-2800 \mathrm{rpm}$ \\
After-treatment system & DOC + c-DPF \\
Emission regulation & Japan post new long term \\
\hline
\end{tabular}




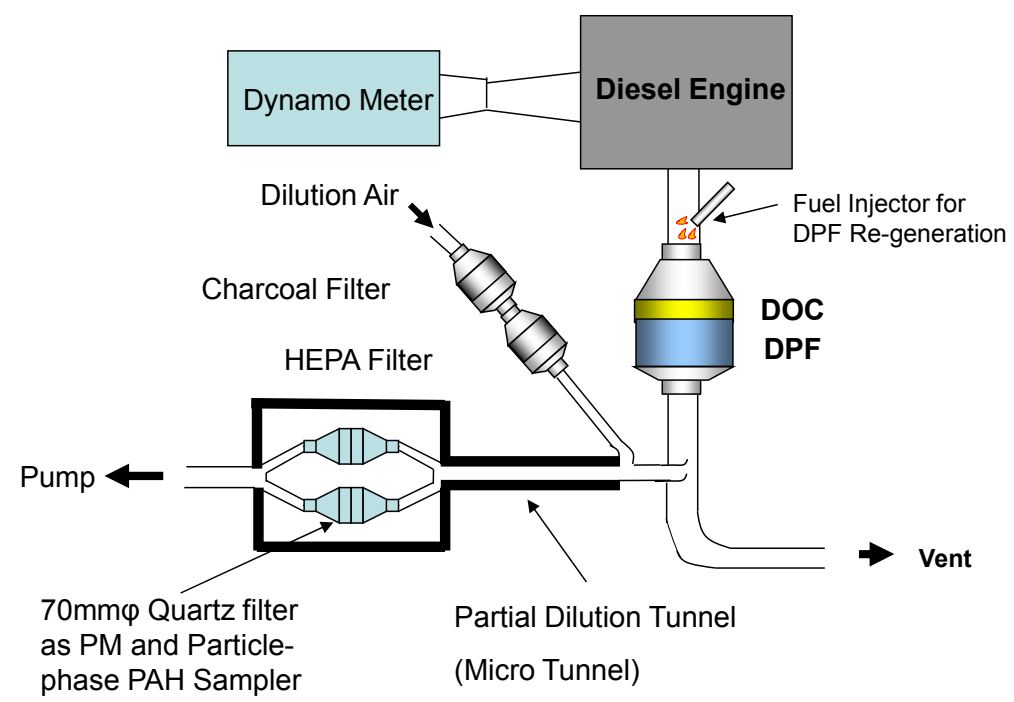

Fig. 1. Test engine and sampling system (c-DPF active regeneration engine operating condition used as an example).

fuel and a D fuel. The main properties of these two fuels are detailed in Table 2. A D fuel is widely used in Japan. A $10 \%$ RME biodiesel blend has a higher cetane number, density, and viscosity, and a lower calorific value than $\mathrm{D}$. Notably, the sulfur content is less than $10 \mathrm{ppm}$ for both fuels.

\section{Particulate Sampling}

We used a partial flow dilution system (MDLT-1302 Micro Dilution Tunnel; HORIBA) to dilute and cool the exhaust for particulate sampling; the flow rate of this was set to $80 \mathrm{~L} \mathrm{~min}^{-1}$. The exhaust division ratio of the partial flow dilution tunnel was held constant at 600 .

Although diesel exhaust particles are usually collected on a Teflon-coated glass-fiber filter, we had to use quartzfiber filters instead because we utilized thermal desorptiongas chromatograph-mass spectrometry (TD-GC-MS) for the analysis of PAHs and a carbon analyzer for the analysis of elemental and organic carbon. Before sampling, the quartz fiber filters (Tissuquartz 2500QAT-UP; Pall Corp.) were baked in an electric furnace while being exposed to atmospheric air for $1 \mathrm{~h}$ at $350^{\circ} \mathrm{C}$. Before and after sampling, the filters were conditioned for $24 \mathrm{~h}$ in a chamber characterized by a controlled temperature and relative humidity: $22 \pm 3^{\circ} \mathrm{C}$ and $40 \pm 5 \%$, respectively. The filters were then weighed with a microbalance $(1-\mu \mathrm{g}$ readability; M3P-F; Sartorius AG, Goettingen, Germany). At the sampling stage, diesel exhaust particulates were collected on a 60-mm-diameter area of a 70-mm-diameter filter. After weighing, the filters were stored at $-80 \pm 2{ }^{\circ} \mathrm{C}$ until analysis.

\section{Measurement of the Size Distribution and Number Concentration of the Exhaust Particles}

The size distribution and number concentration of the diluted exhaust particle emissions were also measured using the Engine Exhaust Particle Sizer (EEPS) 3090 Spectrometer (TSI Inc., MI, USA). This instrument can measure particles from 5.6 to $560 \mathrm{~nm}$ with a high resolution $(10 \mathrm{~Hz})$. The dilution ratio was fixed 10 in all of three engine operating conditions. In addition, sampling method was same in at all samplings.

\section{PAHs Analysis Using Direct-injection Thermal Desorption Gas Chromatography-Mass Spectrometry}

The use of direct-injection thermal desorption (TD) gas chromatography-mass spectrometry (GC-MS) for the analysis of organic compounds, such as PAHs, $n$-alkanes, and $n$-monocarboxylic acids, in atmospheric aerosols or automobile exhaust particles has been reported (Neusüss et al., 2000; Waterman et al., 2000; Falkovich and Rudich, 2001; Hays et al., 2003; Ho and Yu, 2004; Hays et al., 2007; Fushimi et al., 2007; Iwakiri et al., 2007; Lavrich and Hays, 2007; Shibata et al., 2010a, b). TD-GC-MS does not require organic solvent extraction and it relies on direct

Table 2. Properties of the test fuels.

\begin{tabular}{lll}
\hline Type & $10 \%$ RME biodiesel & Petroleum diesel \\
\hline Cetane number & 57.5 & 55.6 \\
Density $\left(\mathrm{g} \mathrm{cm}{ }^{-3}\right)$ & 0.8498 & 0.8303 \\
Viscosity @ $30^{\circ} \mathrm{C}\left(\mathrm{mm}^{2} \mathrm{~s}^{-1}\right)$ & 4.182 & 3.464 \\
Calorific value $\left(\mathrm{kJ} \mathrm{kg}^{-1}\right)$ & 42,760 & 45,850 \\
Sulfur content $(\mathrm{mass} \mathrm{ppm})$ & 6 & 7 \\
Distillation @ 30\% $\left({ }^{\circ} \mathrm{C}\right)$ & 263.5 & 257.5 \\
Distillation @ $50 \%\left({ }^{\circ} \mathrm{C}\right)$ & 288 & 280.5 \\
Distillation@ $80 \%\left({ }^{\circ} \mathrm{C}\right)$ & 326 & 317 \\
\hline
\end{tabular}


sample injection. An effective way of suppressing the adsorption of samples onto the injection wall would be to cool and concentrate the thermally desorbed PAHs upstream of the GC column, followed by TD again (Iwakiri et al., 2007).

To determine and quantify the presence of PAHs in the particle-phase of diesel exhaust, we used and optimized the conditions for TD-GC-MS combined with a cryogenic-focus trap and selected-ion monitoring (SIM). We also utilized a deuterated, mixed internal standard including all each component of PAH of our target of analysis. This analytical method is more effective to acquire good peak separation and high sensitivity compared to organic solvent-Soxhlet extraction and concentration method.

The PAHs were analyzed using a T-Dex II TD system (GL Sciences Inc., Tokyo, Japan) installed on a Bruker GC-3800GC with a 300-MS (Bruker Corp., MA, USA). The TD tube (89-mm length, 4-mm i.d., 6-mm o.d.; Pyrex) was automatically placed in the TD area under the injection port in the upper part of the GC system. The cryogenic-focus trap system was located below the TD area in the GC oven and was cooled initially at $-50^{\circ} \mathrm{C}$ with liquid nitrogen until reheated. We selected $300^{\circ} \mathrm{C}$ as the TD temperature because at this temperature, pyrolysis is suppressed and PAHs on the particle make desorption effective. The TD tube was heated from $45^{\circ} \mathrm{C}$ (for $1 \mathrm{~min}$ ) to $300^{\circ} \mathrm{C}$ (for $10 \mathrm{~min}$ ) at a rate of $5^{\circ} \mathrm{C} \mathrm{s}^{-1}$ by means of a split (1:1)-mode injection. Desorbed compounds were collected in the cryogenicfocus trap at $-50^{\circ} \mathrm{C}$ cooled by liquid nitrogen in a TD tube $(0.53 \mathrm{~mm}$ i.e., inert fused silica capillary column $)$ and reheated from $-50^{\circ} \mathrm{C}$ (for $1 \mathrm{~min}$ ) to $300^{\circ} \mathrm{C}$ (for $10 \mathrm{~min}$ ) at a rate of $50^{\circ} \mathrm{C} \mathrm{s}^{-1}$ and then were sent to capillary column (30-m length, 0.25-mm i.d., 0.25- $\mu \mathrm{m}$ film thickness; VF-5ms; Agilent Technologies, Inc., Santa Clara, LA, USA) The $\mathrm{GC}$ was heated from $60^{\circ} \mathrm{C}$ (for $3 \mathrm{~min}$ ) to $200^{\circ} \mathrm{C}$ at a rate of $15^{\circ} \mathrm{C} \min ^{-1}$ and then to $325^{\circ} \mathrm{C}$ (for $10 \mathrm{~min}$ ) at a rate of $5^{\circ} \mathrm{C} \mathrm{m^{-1 }}$. The helium carrier gas was supplied at

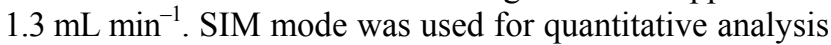
in this study. The GC inlet injector, ion-source, and transfer-line temperatures were $280^{\circ} \mathrm{C}, 230^{\circ} \mathrm{C}$, and $280^{\circ} \mathrm{C}$, respectively. For quantification of the PAHs, a Standard Reference Material solution, SRM 1647e, including sixteen PAHs was purchased from National Institute of Standards and Technology (NIST; Gaithersburg, MD, USA) and diluted with HPLC-grade acetonitrile to prepare calibration curves. In addition, to increase the accuracy of quantification, we used PAH Cocktail for CARB Method 429 as an internal standard solution including sixteen deuterated all-target PAHs purchased from Cambridge Isotope Laboratories, Inc. (CIL; Andover, MA, USA) and diluted with 2,2,4trimethylpentane. Before sampling and after each analysis, the TD tubes were cleaned with acetone for $30 \mathrm{~min}$ at $50^{\circ} \mathrm{C}$ in the ultrasonic bath and dried at $80^{\circ} \mathrm{C}$ in electronic furnace.

A collected particle sample on the quartz filter was punched to be $10 \mathrm{~mm}$ in diameter and placed in the middle of an empty TD tube with glass frit. Additionally, we injected diluted internal standard solution on another 10-mm quartz filter and set into the middle on a TD tube above the sample filter. Twelve 3-6-ring PAHs were analyzed within $1 \mathrm{~h}$.

\section{Elemental and Organic Carbon Analysis Using a Carbon Analyzer}

Elemental carbon (EC) and organic carbon (OC) were analyzed with a thermal/optical carbon analyzer, and implementing the IMPROVE protocol (OC1: $120^{\circ} \mathrm{C}, \mathrm{OC} 2$ : $250^{\circ} \mathrm{C}$, OC3: $450^{\circ} \mathrm{C}$, OC4: $550^{\circ} \mathrm{C}$ (under $100 \% \mathrm{He}$ atmosphere), $\mathrm{EC} 1: 550^{\circ} \mathrm{C}, \mathrm{EC} 2: 700^{\circ} \mathrm{C}, \mathrm{EC}: 800^{\circ} \mathrm{C}$ (under 2\% $\mathrm{O}_{2} / 98 \%$ He atmosphere) (Chow et al., 1993, 2001). Similar to what was done for PAH analysis, an 8-mm hole (with a surface area of $0.503 \mathrm{~cm}^{2}$ ) was punched in the quartz filter containing the collected particle sample, and the filter thus processed was placed in the stage of the carbon analyzer.

\section{RESULTS AND DISCUSSION}

Size Distribution and Number Concentration of Particles

Fig. 2 denotes the size distribution and number concentration of the engine exhaust particle emissions using D fuel and 10\% RME biodiesel blend under the tailpipe-out engine operating condition. Two peaks of each size distribution were observed using D fuel and $10 \%$ RME biodiesel blend. The bimodal peaks were observed at approximately 11 and $70 \mathrm{~nm}$ when $\mathrm{D}$ fuel was used, whereas they were observed at 11 and $110 \mathrm{~nm}$ when $10 \%$ RME biodiesel blend was used. The sizes and number concentrations of the smaller peaks were the same for both fuels; however, those of the larger peaks were different. The larger peak was greater and more spread out and the number concentration was higher while using 10\% RME biodiesel blend than that observed while using $\mathrm{D}$ fuel.

\section{Regulated Emissions}

The amounts of regulated species $\mathrm{CO}, \mathrm{CO}_{2}, \mathrm{THC}$, and $\mathrm{NO}_{\mathrm{x}}$ emitted from the test diesel engine powered with either D fuel or 10\% RME fuel are reported in Fig. 3. The test engine was operated under engine-out, tailpipe-out, and regen conditions.

Under the engine-out operating condition, when the engine was powered with $10 \% \mathrm{RME}$ fuel, the $\mathrm{CO}$ emission levels were slightly higher and the THC emission levels slightly lower than when it was powered with D fuel. Under these two engine operating conditions, no significant differences in emission levels were observed. Under the regen engine operating conditions, no significant differences were observed for the emission levels of $\mathrm{CO}$ and $\mathrm{NO}_{\mathrm{x}}$; however, THC emissions were higher when the engine was powered with $10 \% \mathrm{RME}$ fuel than when it was powered with $\mathrm{D}$ fuel. In addition, $\mathrm{NO}_{\mathrm{x}}$ emission levels under the regen engine operating conditions were determined to be approximately twice those measured under the other two engine operating conditions. It was assumed that this difference was because under the regen engine operating conditions, the temperature of the exhaust rises above $550^{\circ} \mathrm{C}$.

Some researchers have reported that various types of biodiesel blends can improve the combustion efficiency and reduce emissions of $\mathrm{CO}$, THC, PAHs, and PM with respect to D fuels (Zhang et al., 2011; Tsai et al., 2014). In the case of the low-percentage RME blend fuel that has been 


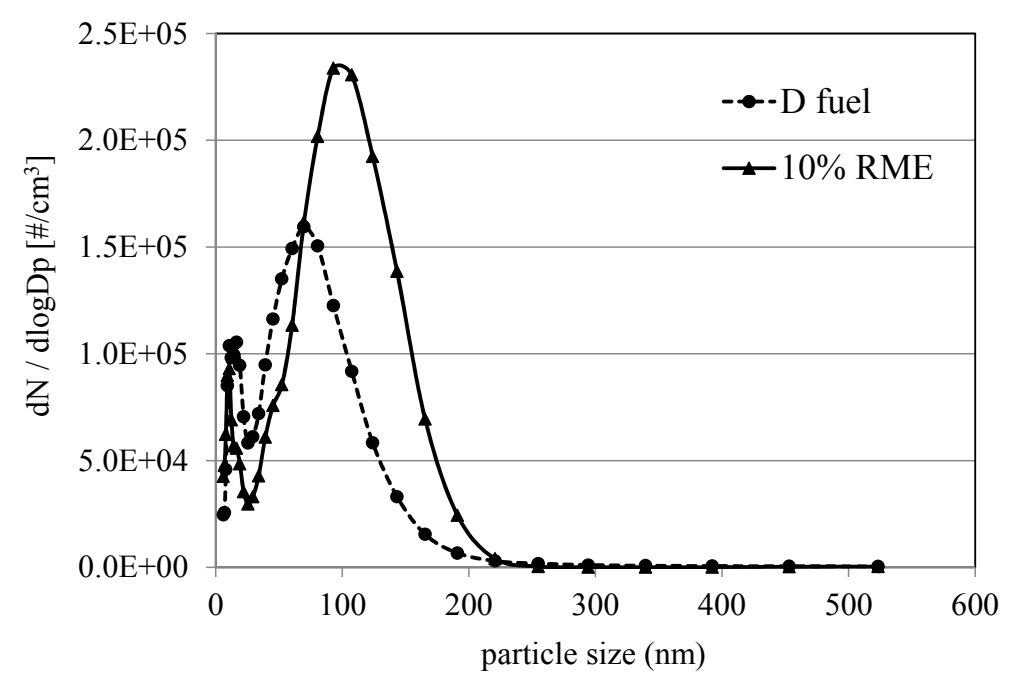

Fig. 2. Size distribution and number concentration of the tailpipe-out exhaust particle emissions using petroleum diesel (D) fuel and 10\% RME biodiesel blend.

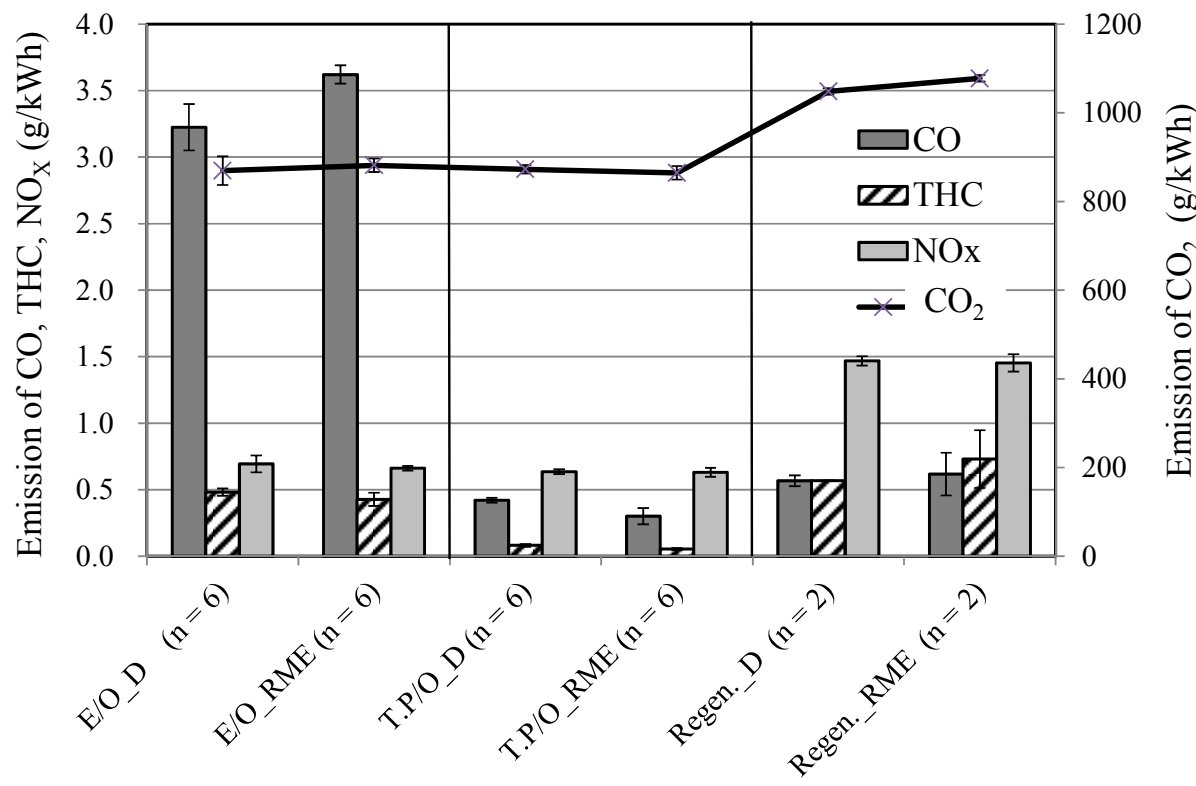

Fig. 3. Emissions of $\mathrm{CO}, \mathrm{CO}_{2}$, total hydrocarbons (THC), and $\mathrm{NO}_{\mathrm{x}}$ associated with the use of petroleum diesel (D) fuel or $10 \%$ RME fuel to power a test engine operated under three different conditions: engine-out (E/O), tailpipe-out (TP/O), and regeneration (regen).

utilized in this study, under engine-out and tailpipe-out operating conditions, no significant changes in the level of $\mathrm{NO}_{\mathrm{x}}$ emissions were observed with respect to the case of the engine powered with $\mathrm{D}$ fuel. By contrast, under the mentioned engine operating conditions, the THC emissions were lower when 10\% RME biodiesel blend was used than when D fuel was used, a result consistent with those of the research reports alluded to above. Except for the case of the engine-out operating conditions, the $\mathrm{CO}$ emission levels either were lower when 10\% RME biodiesel blend was used or displayed no significant difference. It was assumed that these results were because biodiesel blend fuels contain more oxygen than D fuels, so that biodiesel can be more easily oxidized than $\mathrm{D}$, leading to a reduction in the amount of adsorbed HC and OC. Under the regen engine operating conditions, the emission levels of $\mathrm{CO}$, and THCs were higher than their counterparts measured under the tailpipe-out engine operating conditions.

To regenerate c-DPF and clean it up from adsorbed soot particles, it is necessary to raise the DOC inlet temperature above $250^{\circ} \mathrm{C}$ so as to trigger catalyst activation. Because the $10 \%$ RME biodiesel blend has a $6.7 \%$ lower calorific value than $\mathrm{D}$, under the regen engine operating conditions, the amount of $10 \%$ RME biodiesel fuel consumed before reaching the target temperature was $5 \mathrm{~g} \mathrm{kWh}^{-1}$ higher than the corresponding consumed amount of D fuel. Therefore, it was considered that the THC emissions for $10 \% \mathrm{RME}$ fuel were higher than those for $\mathrm{D}$ fuel. The additional fuel 
consumption observed under regeneration conditions with respect to the non-regeneration conditions when 10\% RME biodiesel blend was used as the fuel was $293 \mathrm{~g} \mathrm{test}^{-1}$, whereas this parameter was $263 \mathrm{~g} \mathrm{test}^{-1}$ when D fuel was used instead. We also measured total thermal energy consumption of the combustion associated with the use of the two fuels: The value for this parameter was $12,544 \mathrm{~kJ}$ test $^{-1}$ while using the $10 \%$ RME biodiesel blend and was $12,048 \mathrm{~kJ}^{\text {test }}{ }^{-1}$ while using the $\mathrm{D}$ fuel. In summary, thermal energy consumption of $10 \%$ RME was slightly higher than that released by $\mathrm{D}$ fuel. Under the regen engine operating conditions, the evidence thus indicates that the higher THC emissions observed when the 10\% RME biodiesel blend was used is the result of a higher fuel consumption level per test. In addition, during the regeneration period of the test mode, the collected particles and the soluble organic fraction (SOF) adsorbed on the particles on the c-DPF are oxidized and are hardly discharged post c-DPF; however, after the regeneration is completed, the amount of emissions will increase. This effect results from the fact that immediately after regeneration, the particle collection efficiency of c-DPF decreases markedly because particles cannot be collected completely.

\section{EC and $\mathrm{OC}$ emissions}

The upper part of Fig. 4 reports the observed emissions of carbonaceous compounds (EC and OC) associated with the use of $\mathrm{D}$ fuel and 10\% RME biodiesel blend under the three different engine operating conditions. EC2 was the most abundant carbonaceous component in the diesel exhaust particles when the engine-out operating conditions were implemented, and it was also the carbonaceous component for which the largest relative reduction was observed when 10\% RME biodiesel blend was used instead of D fuel. By contrast, no significant differences were observed between pairs of the other EC and OC
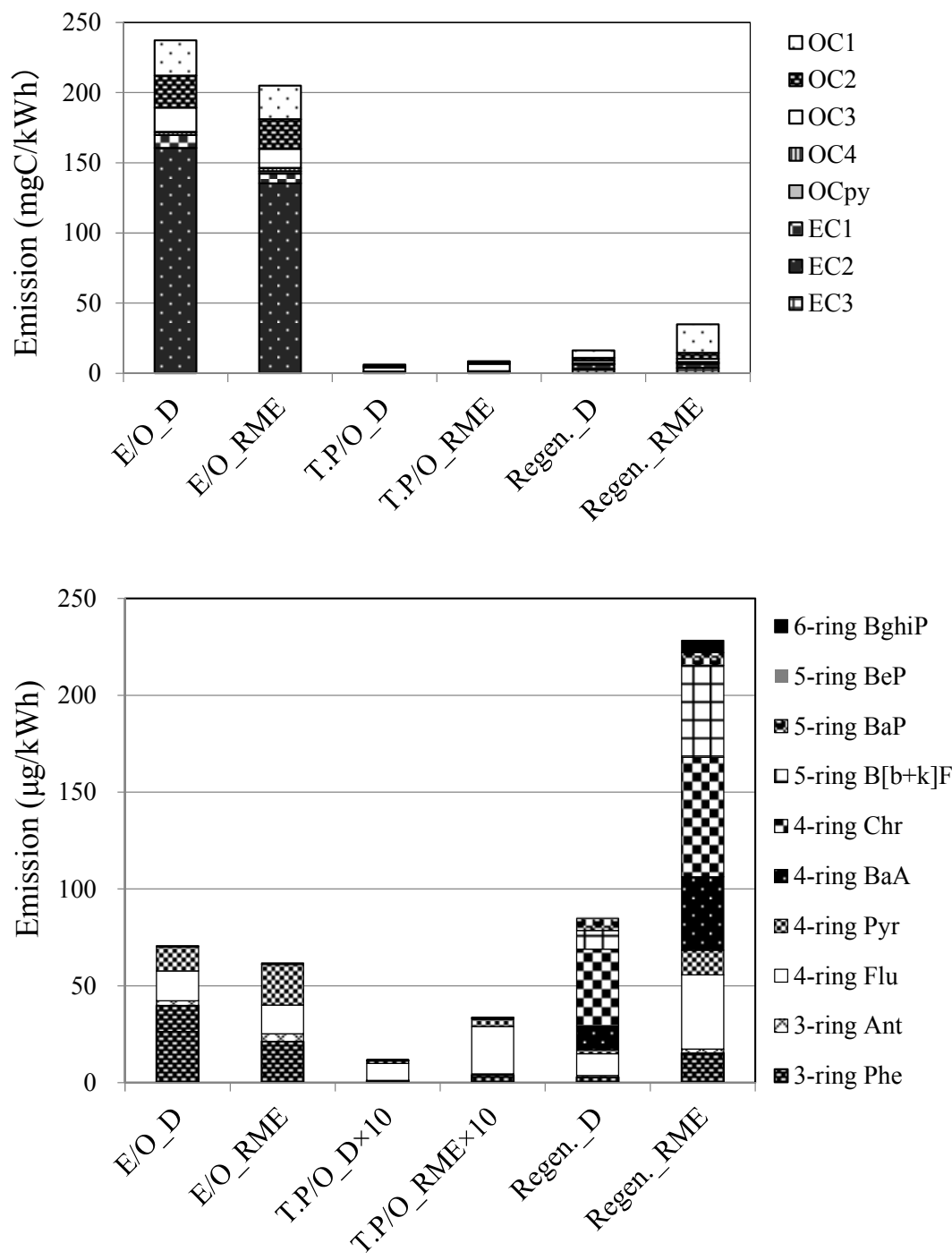

Fig. 4. Emissions of carbonaceous compounds, elemental carbon (EC) and organic carbon (OC) (upper graph), and particle-phase emissions of the three- to six-ringed polycyclic aromatic hydrocarbons (lower graph) associated with the use of petroleum diesel (D) fuel or 10\% RME biodiesel blend to power a test engine operating under three different conditions: engine-out (E/O), tailpipe-out (TP/O), and regeneration (regen). 
components analyzed when 10\% RME biodiesel blend was used instead of D fuel to power the test engine operated under the engine-out conditions. Under the tailpipe-out condition, none of the EC or OC components of $10 \% \mathrm{RME}$ fuel changed significantly when 10\% RME biodiesel blend was used instead of $\mathrm{D}$ fuel. The reduction in the amounts of EC and OC made possible by the after-treatment system were $99.7 \%$ and $91.8 \%$, respectively, when using the D fuel, and $99.5 \%$ and $87.8 \%$, respectively, when using the $10 \%$ RME biodiesel blend. The evidence therefore indicated that the reduction in $\mathrm{OC}$ levels by the after-treatment system was lower when 10\% RME was utilized than when the D fuel was utilized. These results are likely to reflect the different properties of the two fuels. Under the regen engine operating conditions, the $\mathrm{OC} 1$ and $\mathrm{OC} 2$ emissions were higher when using the 10\% RME biodiesel blend than when using the D fuel. It was assumed that the $\mathrm{OC} 1$ and $\mathrm{OC} 2$ contained fuel components that would increase in amount as a result of an increase in fuel consumption. However, because it was not clear whether differences in fuel consumption are the cause of these disparities, the carbonaceous compound emissions per consumed fuel unit calculated.
The upper part of Fig. 5 reports the observed amount for regeneration condition minus non-regeneration conditions for carbonaceous compounds using D fuel and 10\% RME fuel. Evidence indicates that the $\mathrm{OC} 1$ and $\mathrm{OC} 2$ emissions increased significantly from the first scenario to the second; this observation is assumed to result from a decrease in the oxidation capacity of $10 \%$ RME biodiesel blend due to its poor calorific value, and low exhaust temperature during the initial regeneration period.

\section{PAH Emissions}

PAHs are distributed between the gas and particle-phase based on their vapor pressure and atmospheric temperature. The two-ringed naphthalene exists almost exclusively in the gas phase, whereas the five- and six-ringed PAHs are predominantly adsorbed on particles. The intermediately sized three- and four-ringed PAHs are distributed between the two phases (Zielinska et al., 2004).

The lower part of Fig. 4 reports data on the particle-phase emissions from the three- to six-ringed PAHs obtained using either 10\% RME biodiesel blend or D fuel. In case of the engine-out operating conditions, particle-phase phenanthrene (Phe) emitted when the test engine was powered by $10 \%$

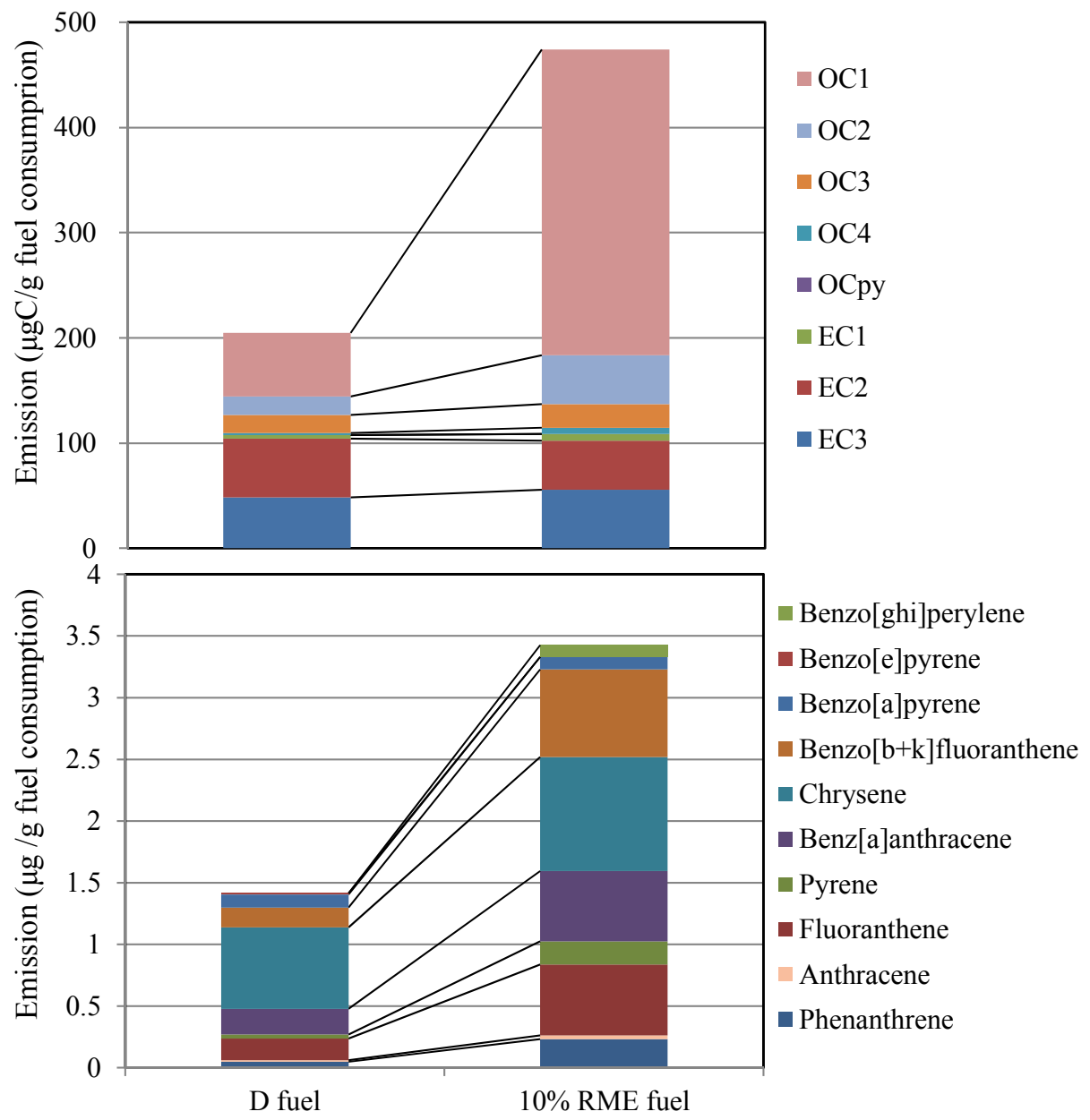

Fig. 5. The difference in amount between the regeneration condition and the non-regeneration conditions (the former minus the latter) for carbonaceous compounds (upper graph) and individual polycyclic aromatic hydrocarbons (PAHs) (lower graph) using D fuel and 10\% RME fuel. 
RME biodiesel blend was half the amount emitted when the engine was powered by D fuel. Conversely, the amount of particle-phase anthracene (Ant) increased slightly when D fuel was replaced with 10\% RME biodiesel blend. Overall, when applying the engine-out operating conditions, the total emissions of the three-ringed PAHs were lower when using 10\% RME biodiesel blend than when using D fuel. It is considered that the reason is $10 \% \mathrm{RME}$ fuel contains more oxygen atoms than $\mathrm{D}$ fuel. In contrast, these three-ringed PAHs were shown to be scarcely discharged in the particle phase when the tailpipe-out engine operating conditions were used by the oxidation of the catalyst and filter effect. Additionally, the reduction in the amount of Phe and Ant emitted in the particle phase resulting from the installation of the after-treatment system was very high for both fuels: $99.7 \%$ and $100.0 \%$, respectively, for D fuel, and $98.2 \%$ and $98.3 \%$, respectively, for $10 \% \mathrm{RME}$ biodiesel blend. Under the regen engine operating conditions, the amount of particle-phase three-ringed PAHs when 10\% RME biodiesel blend was utilized were emitted more than when $\mathrm{D}$ fuel was utilized. As the calorific value of $10 \%$ RME biodiesel blend is $6.7 \%$ lower than that of D fuel, it took longer for the c-DPF to reach the target temperature for regeneration $\left(>550^{\circ} \mathrm{C}\right)$ when $10 \%$ RME biodiesel blend was utilized than when D fuel was utilized. As the result, the total fuel consumption during JE05-test cycle regeneration was higher when $10 \%$ RME biodiesel blend was utilized than when D fuel was utilized. Notably, the total particle-phase emission of the three-ringed PAHs under the regen engine operating conditions were lower than those observed when engineout operating conditions were implemented.

Under the engine-out operating conditions, the particlephase four-ringed fluoranthene (Flu) emissions were similar in case of both the fuels but the particle-phase four-ringed pyrene (Pyr) emissions were higher when 10\% RME biodiesel blend was used to power the test engine. Under the tailpipe-out engine operating conditions, the particlephase Flu emissions were also higher when 10\% RME fuel was used to power the test engine. This evidence suggests, therefore, that the use of $10 \%$ RME fuel results in incomplete combustion caused by its poor evaporation and it is believed the ratio of SOF/soot is higher compared with $\mathrm{D}$ fuel. The reductions in particle-phase Flu and Pyr emissions achieved by the after-treatment system were 94.3\% and 99.1\% when D fuel was utilized, and $83.5 \%$ and $98.2 \%$, respectively, when 10\% RME biodiesel blend was utilized. Therefore, when using 10\% RME biodiesel blend, the reductions in particle-phase Flu and Pyr emissions resulting from the use of the after-treatment system are lower than their counterparts observed for three-ringed PAHs. The particle-phase emissions of the other two fourringed PAHs investigated ( $\mathrm{BaA}$ and $\mathrm{Chr}$ ) are too low for their reductions associated with the use of the aftertreatment system to be evaluated. Notably, under the regen engine operating conditions, the particle-phase emissions of all four four-ringed PAHs targeted for analysis in this study increased significantly when 10\% RME biodiesel blend was utilized to power the test engine instead of D fuel. Furthermore, the period of regeneration observed to be necessary when using $10 \%$ biodiesel blend was longer than its counterpart observed when using $\mathrm{D}$ fuel. The difference caused fuel consumption and the particle-phase emissions of some PAHs to increase when 10\% RME biodiesel blend was used instead of $\mathrm{D}$ fuel.

Under the engine-out and tailpipe-out engine operating conditions, none of the five- and six-ringed PAHs benzo $(b+k)$ fluoranthene $(\mathrm{B}(b+k) \mathrm{F})$, benzo $(a)$ pyrene $(\mathrm{BaP})$, and benzo $(g, h, i)$ perylene (BghiP) was actually detected; however, under the regen engine operating conditions, the $\mathrm{B}(b+k) \mathrm{F}$ and BghiP emissions increased when 10\% RME biodiesel blend was utilized to power the test engine instead of D fuel. The particle-phase emissions of some of the three-, four-, and five-ringed PAHs in the case of 10\% RME fuel also increased on the regeneration condition because the filter collection efficiency decreases immediately after the regeneration period, and the particles slip through c-DPF.

The lower part of Fig. 5 reports the observed regeneration amount minus the non-regeneration amount for selected PAHs while using D fuel and 10\% RME fuel. The emissions of eight PAHs contained in SOF increased in the incomplete combustion of $10 \%$ RME biodiesel blend.

\section{CONCLUSIONS}

The emissions of both regulated and unregulated species, viz., $\mathrm{CO}, \mathrm{CO}_{2}, \mathrm{THC}, \mathrm{NO}_{\mathrm{x}}, \mathrm{EC}, \mathrm{OC}$, and PAHs, from a modern diesel engine equipped with an after-treatment system (consisting of a diesel oxidation catalyst and a c-DPF) and powered by either a 10\% RME biodiesel blend or petroleum diesel fuel were quantified for three different states: when the after-treatment system was deployed (engineout), when the after-treatment system was not deployed (tailpipe-out), and when the after-treatment system was deployed and the c-DPF was regenerating (regen). Although switching between the states while using the biodiesel blend showed no significant effects on the regulated emissions of $\mathrm{CO}, \mathrm{CO}_{2}, \mathrm{THC}$, and $\mathrm{NO}_{\mathrm{x}}$, some differences were detected in the unregulated emissions of EC, OC, and PAHs.

The analysis results of the carbonaceous components indicated that during engine-out, the EC2 emissions were slightly lower while using the 10\% RME biodiesel blend than the diesel fuel. Notably, EC2 was also the most abundant EC component identified in the diesel exhaust. However, the OC1 and OC2 emissions increased during regen while using the biodiesel blend because of large fuel consumption. The filter collection efficiency also decreased in the period immediately following regeneration, allowing particles to slip through the c-DPF; in particular, we observed more three-, four-, and five-ringed PAHs. Despite this increase, the amount of PAHs emitted by the engine was very small compared to that of carbonaceous components (EC and OC) while using the biodiesel blend. The c-DPF also required a longer regeneration period with the blend than with the petroleum diesel fuel.

Substituting diesel fuel with this biodiesel blend reduces the emission of EC2 for engines without an after-treatment system without significantly increasing the emission of 
EC, OC, and PAHs for engines with an after-treatment system. Although, as aforementioned, the emissions of OC1, OC2, and some PAHs actually increased during the regeneration phase with the biodiesel blend, presumably as a result of its decreased oxidation capacity at low exhaust temperatures due to its lower calorific value, these issues can be resolved by improving the control technology for c-DPFs and reducing the frequency of regeneration.

\section{ACKNOWLEDGMENTS}

The authors thank Mr. Kentarou Kanno from Isuzu Advanced Engineering Center, Ltd. for assistance with engine operation and calibration.

In addition, the authors would also like to thank Enago (www.enago.jp) for the English language review.

\section{SUPPLEMENTARY MATERIAL}

Supplementary data associated with this article can be found in the online version at http://www.aaqr.org.

\section{REFERENCES}

Ajtai, T., Pintér, M., Utry, N., Kiss-Albert, G., Gulyás, G., Pusztai, P., Ruskás, R., Bereczky, Á., Szabados, Gy., Szabó, G., Kónya, Z. and Bozóki, Z. (2016). Characterisation of diesel particulate emission from engines using commercial diesel and biofuels. Atmos. Environ. 134: 109-120.

Babu, A.K. and Devaradjane, G. (2003). Vegetable oils and their derivatives as fuels for CI engines: An overview. SAE Tech. Paper 2003-01-0767.

Bhavaraju, L., Jonathan Shannahan, J., William, A., McCormick, R., McGee, J., Kodavanti, U. and Madden, M. (2014). Diesel and biodiesel exhaust particle effects on rat alveolar macrophages with in vitro exposure. Chemosphere 104: 126-133.

Chien, S.M., Huang, Y.J., Chuang, S.C. and Yang, H.H. (2009). Effects of biodiesel blending on particulate and polycyclic aromatic hydrocarbon emissions in nano/ultrafine/fine/coarse ranges from diesel engine. Aerosol Air Qual. Res. 9: 18-31.

Chow, J.C., Watson, J.G., Pritchett, L.C., Pierson, W.R., Frazier, C.A. and Purcell, R.G. (1993). The DRI thermal/optical reflectance carbon analysis system: Description, evaluation and applications in U.S. air quality studies. Atmos. Environ. 27: 1185-1201.

Chow, J.C., Watson, J.G., Lowenthal, D.H. and Merrifield, T. (2001). Comparison of IMPROVE and NIOSH carbon measurements. Aerosol Sci. Technol. 34: 23-34.

Falkovich, A.H. and Rudich, Y. (2001). Analysis of semivolatile organic compounds in atmospheric aerosols by direct sample introduction thermal desorption GC/MS. Environ. Sci. Technol. 35: 2326-2333.

Fushimi, A., Tanabe, K., Hasegawa, S. and Kobayashi, S. (2007). Investigation of characterization method for nanoparticles in roadside atmosphere by thermal desorption-gas chromatography/mass spectrometry using a pyrolyzer. Sci. Total Environ. 386: 83-92.

Hays, M.D., Smith, N.D., Kinsey, J., Dong, Y. and Kariher, P. (2003). Polycyclic aromatic hydrocarbon size distributions in aerosols from appliances of residential wood combustion as determined by direct thermal desorption-GC/MS. J. Aerosol Sci. 34: 1061-1084.

Hays, M.D. and Lavrich, R.J. (2007). Developments in direct thermal extraction gas chromatography mass spectrometry of fine aerosols. TrAC, Trends Anal. Chem. 26: 88-102.

He, B.Q. (2016). Advances in emission characteristics of diesel engines using different biodiesel fuels. Renewable Sustainable Energy Rev. 60: 570-586.

Ho, S.S.H. and Yu, J.Z. (2004). In-injection port thermal desorption and subsequent gas chromatography-mass spectrometric analysis of polycyclic aromatic hydrocarbons and $n$-alkanes in atmospheric aerosol samples. J. Chromatogr. A 1059: 121-129.

Iwakiri, Y., Kanno, H. and Koyama, H. (2007). A study of an analysis method for trace substances in vehicle exhaust gas. SAE Tech. Paper 2007-01-0316.

Kinoshita, E., Myo, T., Hamasaki, K., Tajima, H. and Kun, Z.R. (2006). Diesel combustion characteristics of coconut oil and palm oil biodiesels. SAE Tech. Paper 2006-013251.

Lavrich, R.J. and Hays, M. D. (2007). Validation studies of thermal extraction-GC/MS applied to source emissions aerosols. 1. Semivolatile analyte-nonvolatile matrix interactions. Anal. Chem. 79: 3635-3645.

Neusüss, C., Pelzing, M., Plewka, A. and Herrmann, H. (2000). A new analytical approach for size-resolved speciation of organic compounds in atmospheric aerosol particles: Methods and first results. J. Geophys. Res. 105: 4513-4527.

Peters, A., Wichmann, H.E., Tuch, T., Heinrich, J. and Heyder, J. (1997). Respiratory effects are associated with the number of ultrafine particles. Am. J. Respir. Crit. Care Med. 155: 1376-1383.

Robbins, C., Hoekman, S.K., Ceniceros, E. and Natarajan, M. (2011). Effects of biodiesel fuels upon Criteria emissions. SAE Tech. Paper 2011-01-1943.

Shibata, K., Yanagisawa, N., Tashiro, Y., Mukunashi, T., Onodera, T. and Sakamoto, K. (2010a). Decline of emission and carcinogenic potency of polycyclic aromatic hydrocarbons by diesel oxidation catalyst and catalyzed diesel particulate filter. J. Health Sci. 56: 3140.

Shibata, K., Yanagisawa, N., Tashiro, Y. and Sakamoto, K. (2010b). Emission characteristics of polycyclic aromatic hydrocarbons in diesel particles-effectiveness of diesel oxidation catalyst -. J. Jpn Soc. Atmos. Environ. 45: 144-152 (in Japanese).

Sze, C., Whinihan, J.K., Brian A. Olson, B.A., Charles R. Schenk, C.R. and Sobotowski, R.A. (2007). Impact of test cycle and biodiesel concentration on emissions. SAE Tech. Paper 2007-01-4040.

Tsai, J.H., Chen, S.J., Huang,K.L., Lin, W.Y., Lee, W.J., Lin, C.C., Hsieh, L.T., Chiu, J.Y. and Kuo, W.C. (2014). Emissions from a generator fueled by blends of 
diesel, biodiesel, acetone, and isopropyl alcohol: Analyses of emitted PM, particulate carbon, and PAHs. Sci. Total Environ. 466-467: 195-202.

Waterman, D., Horsfield, B., Leistner, F., Hall, K. and Smith, S. (2000). Quantification of polycyclic aromatic hydrocarbons in the NIST standard reference material (SRM1649A) Urban dust using Thermal Desorption GC/MS. Anal. Chem. 72: 3563-3567.

Zhang, J., He, K., Shi, X. and Zhao, Y. (2011). Comparison of particle emissions from an engine operating on biodiesel and petroleum diesel. Fuel 90: 2089-2097.

Zheng, M., Mulenga, M.C., Reader, G.T., Wang, M. and Ting, D.S.K. (2006). Influence of biodiesel fuel on diesel engine performance and emissions in low temperature combustion. SAE Tech. Paper 2007-01-3281.
Zhong, W., Xuan, T., He, Z., Wang, Q., Li, D., Zhang, X. and Yin, H.Y. (2016). Experimental study of combustion and emission characteristics of diesel engine with diesel/second-generation biodiesel blending fuels. Energy Convers. Manage. 121: 241-250.

Zielinska, B., Sagebiel, J., Arnott, W. P., Rogers, C.F., Kerry, K.E., Wagner, D.A., Lighty, J.S., Sarofim, A.F. and Palmer, G. (2004). Phase and size distribution of polycyclic aromatic hydrocarbons in diesel and gasoline vehicle emissions. Environ. Sci. Technol. 38: 2557-2567.

Received for review, January 28, 2019

Revised, May 24, 2019

Accepted, June 4, 2019 